\title{
REACTIVITY OF FUNCTIONAL AMINO ACID RESIDUES IN SILK FIBROIN OF PHILOSAMIA CYNTHIA RICINI TOWARDS MONOEPOXIDES
}

\author{
By Yoshio Tanaka*1, and Hideki Shiozaki ${ }^{* 2}$ \\ *1 (Research Institute for Polymers and Textiles, 1-1-4 Higashi, Tsukuba, Ibaraki 305) \\ *2 (Textile Research Institute of Kanagawa, Aikoh, Kanagawa 243-03, Japan)
}

\begin{abstract}
The heterogeneous addition reaction of the silk fibroin fibers of Philosamia cynthia ricini with various monoepoxides was investigated in ethanol and cyclohexane at $45-75^{\circ} \mathrm{C}$ after the fibers were padded with aqueous solutions of various salts as catalysts. The reactivity of the main functional amino acid residues was found to decrease in the order: histidine, tyrosine, arginine. The concentration of the aqueous salt solutions influenced the reactions of tyrosine and arginine, but did not affect largely those of histidine and lysine. The reaction rate of tyrosine was discussed in terms of the nucleophilicity of the anions of the catalyst. The reactions of tyrosine and histidine depended on both of the polar and steric factors of the substituents of the epoxides. Their effect was elucidated by the modified Taft equation. The reactivity difference of tyrosine, arginine, and histidine between Philosamia cynthia ricini and Bombyx mori silk fibroins towards the epoxide was partly explained with swellability and intermicellar distance of the fibroin fibers and the amino acid composition of the fibers.
\end{abstract}

\section{INTRODUCTION}

In the salt-catalyzed heterogeneous addition reaction of various monoepoxides with the silk fibroin of Bombyx moni, the reactivity of the functional amino acid residues, such as tyrosine, arginine, lysine, and histidine, of the polypeptide chains has been found to depend on the nature of the salt inos, the solvents, and the epoxides, the reactivity of the aliphatic hydroxyl group being neglig. ibly small ${ }^{1-6}$. Since the Bombyx mori silk fibroin contains too small amounts of lysine, histidine, and arginine to permit the reactivity of these amino acid residues to be elucidated kinetically, the epoxide-silk fibroin reaction can be described mainly by the reactivity of the tyrosine residue of the fibroin.

There are similar amounts of tyrosine, and much larger amounts of basic and acidic amino acid residues in the silk fibroin of Philosamia cynthia ricini (eri silk) than those in the Bombyx mori silk fibroin ${ }^{7}$. The aspect of the reaction, therefore, may differ between these two silk fibroins. Indeed, the reactivity of the epoxide towards the silk fibroin of Philosamia cynthia ricini has been observed to be higher than towards the Bombyx mori fibroin ${ }^{8.9}$. The larger amount of the epoxide addition to the Philosamia cynthia ricini silk fibroin seems to be associated with lar ger intermicellar distance and significant ability of the silk fibroin to swell with aqueous solution ${ }^{10}$, besides lar. ger amounts of the reactive amino acid residues, such as tyrosine, histidine, lysine, arginine, and aspartic acid Thus, the reactivity of these reactive amino acid residues should be different between these two silk fibroins. Con sequently, this paper attempts to elucidate the reactivity of these amino acid residues, especially, tyrosine, histi dine, and arginine in the Philosamia cynthia ricini fibroin towards the monoepoxides in comparison with that of Bombyx mori fibroin. 


\section{EXPERIMENTAL}

\subsection{Materials}

Cocoons of Philosamia cynthia ricini were boiled successively with a $2.5 \%$ aqueous solution of sodium car. bonate for $1 \mathrm{hr}$ and with an aqueous solution containing $2 \%$ of Marseilles soap and $1 \%$ sodium carbonate for 1 $\mathrm{hr}$, neutralized with diluted aqueous acetic acid solution, and then rinsed several times with warm distilled water The degummed silk fibroin was extracted first with etha nol, then with ether at room temperature for $24 \mathrm{hr}$, and finally rinsed with distilled water. Before use the purified, air-dried fibroin was dried in an oven at $105^{\circ} \mathrm{C}$ for $45 \mathrm{~min}$, placed in a desiccator over silica gel for $30 \mathrm{~min}$., and was weighed accurately.

Epoxides were all of reagent grade and used after distillation under reduced pressure. These epoxides are 1,2 epoxypropane (PO), 1,2-epoxybutane ( $\mathrm{BO}), 2,2$-dimethyloxirane (iBO), 1,2-epoxyoctane (OO), 2,3-epoxypropan-1-ol (G), 2,3-epoxypropan-1-amide (GAm), 2,3-epoxy propan-1-al (GAl), phenyloxirane (SO), 1-chloro-2,3-epoxypropane (E), 1-bromo-2,3-epoxypropane (Eb), 1,2-epo$x y$-3-(2-propenoxy)propane (AGE), 1,2-epoxy-3-methoxypropane (MGE), 1,2-epoxy-3-ethoxypropane (EGE), 1 . butoxy-2,3-epoxypropane (BGE), 1,2-epoxy-3-(1-methylethoxy)-propane (iPrGE), 2,3-epoxypropyl acry. late (GA), 2,3-epoxypropyl methacrylate (GMA), 1,2 epoxy-3-phenoxypropane (PGE), 1,2-epoxy-3-(4-methylphenoxy)propane (pTGE), and 1,2-epoxy-3-(2-phenylphenoxy)propane (PPGE). All other chemicals were of reagent grade and were used without further purification.

\subsection{Reaction Procedure}

A dried and weighed fibroin sample (ca. $0.4 \mathrm{~g}$ ) was im pregnated and squeezed with an aqueous salt solution to an approximated $100 \%$ wet pickup through a roller mangle. The loosely rolled sample was then placed in a flask containing a $1.43 \mathrm{M}$ solution of an epoxide in ethanol or cyclohexane. The flask was joined with a reflux conde nser, and held in a thermostatically controlled bath. The reaction was carried out at a desired temperature for va rious periods with the flask shaken occassionally.

At the end of the reaction, the sample was rinsed with the same kind of solvent as that used in the reaction, fol. lowed with acetone, and then extracted with boiling ace tone for $30 \mathrm{~min}$, washed with methanol and finally with water. Thus, the remaining epoxide and its oligomer were removed completely from the sample and could be recovered easily. No oligomers, not bound to fibroin, were de tected on further extraction of the fiber with boiling ace. tone or tetrahydrofuran for several hours. The washed and air.dried samples were dried in an oven at $105^{\circ} \mathrm{C}$ for $45 \mathrm{~min}$, placed in a desiccator over silica gel for 30 min and weighed accurately. This drying process was sufficient to attain weight constancy for the determination of incorporated epoxides: The extent of the addition of the epoxide was determined from the weight increase of the samples, a correction being made for the weight loss on treatment without epoxides.

\subsection{Amino Acid Analysis}

Dried fibroin Philosamia cynthia ricini (ca. $200 \mathrm{mg}$ ), un. treated or treated with epoxides, was hydrolyzed by heating for $8-16 \mathrm{hr}$ at $105-108^{\circ} \mathrm{C}$ in $20 \mathrm{ml}$ of $6 \mathrm{~N} \mathrm{HCl}$. An undissolved residue of the firbroin $(10 \%$ or less of total fibroin) was filtered off from the hydrolyzates. The residue was hydrolyzed further and found to consist almost of alanine only by the amino acid analysis.

The amino acid contents were determined with a buffer solution $(\mathrm{pH}=2.2)$ of the hydrolyzate $(0.3-0.4 \mathrm{mg} / \mathrm{ml})$ by use of a JLC-5AH amino acid analyzer (JEOK Ltd.). Basic amino acids such as histidine, lysine, or arginine were determined with 3 to 5 fold concentrated solutions of the hydrolyzates $(1-2 \mathrm{mg} / 0.8 \mathrm{ml})$. On the hydrolysis of the untreated fibroin for 8,12 and $16 \mathrm{hr}$, the contents of the reactive amino acid residues varied as (amino acid contents in mole $/ 10^{5} \mathrm{~g}$ ) Arg., 18.5, 18.5, 18.6; Asp., 40.1, 40.1, 41.0; Glu., 8.0, 8.7, 7.8; His., 16.4, 16.0, 15.9; Lys., 3.1, 3.2, 3.2; Ser. 74.5, 73.4, 73.7; Tyr. $63.7,64.2,64.3$. Thus, the hydrolysis for $12 \mathrm{hr}$ was adopted to be suitable for determination of these reactive amino acid residues in the Philosamia cynthia ricimi fib. roin as reported previously ${ }^{8}$.

\section{RESULTS}

The amino acid contents were determined on an amino acid analyzer for the silk fibroin fibers treated with or without various epoxides in different conditions. On treating the silk fibroin with epoxides, the peak areas of tyrosine, arginine and histidine were markedly reduced in the ion exchange chromatograms of the hydrolyzates from those of the untreated fibroin. This implies a loss of these amino acid residues from the silk fibroin and ind cates that these residues reacted with the epoxide and 


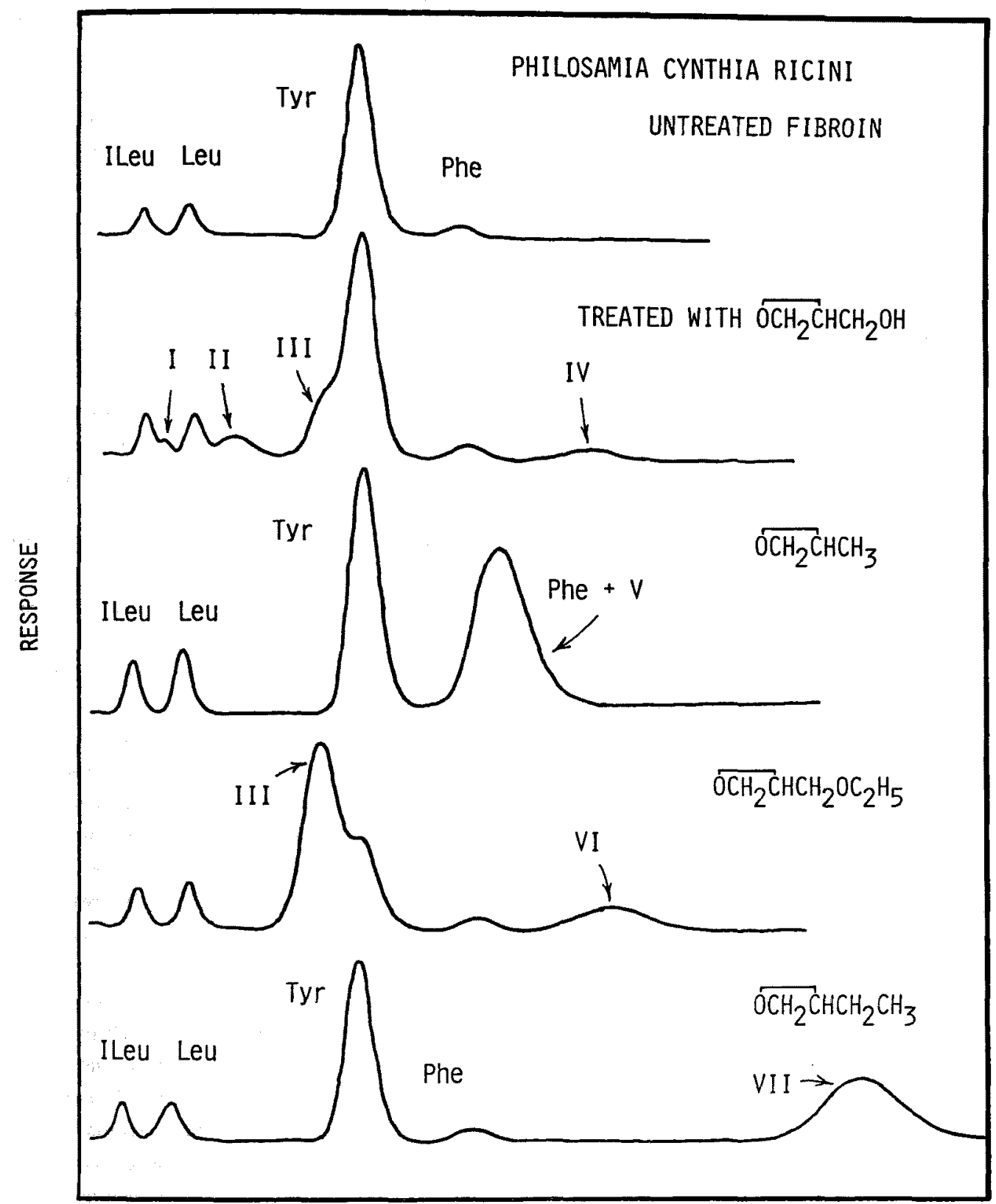

\section{ELUTION VOLUME}

Fig. 1 Automatic ion exchange chromatogram of the hydrolyzates of Philosamia cmthia ricini silk fibroins untreated and treated with G, PO, EGE, and BO: I. O-(2,3-dichloropropyl)tyrosine (tentatively estimated but not identified); II, O-(3-chloro-2-hydroxypropyl)tyrosine ${ }^{11} ;$ III, O-(2.3-dihydroxypropy])tyrosine ${ }^{11} ;$ IV, O- [2. hydroxy-3-(2.3-dihydroxypropoxy)propyl] tyrosine (tentatively estimated but not identified): V. O.(2-hydroxy. propyl)tyrosine ${ }^{11} ; \quad 0-\left(2\right.$-hydroxy-3-ethoxypropyl)tyrosine ${ }^{11}$ : VII, O-(2-hydroxybutyl)tyrosine ${ }^{11}$. 
were modified so that on hydrolysis and elution from an ion exchange column of the analyzer the modified amino acids eluted at different positions from those of unmod. ified amino acids. On the other hand, the peak areas of aspartic and glutamic acids were unaltered in the chromatograms; this does not imply that these acidic residues were not modified by the treatment with the epoxide. The carboxyl groups of these residues should react with the epoxides to produce the ester groups, which can change into the original amino acids under the hydrolysis condition. Thus, the peak areas did not alter. The modification of these acidic residues, however, can be estimated by the gas chromatographic study ${ }^{11}$.

Figure 1 shows some ion-exchange chromatograms of the hydrolyzates of the Philosamia cynthia ricini silk fibroin untreated and treated with some epoxides. In the chromatogram of the fibroin treated with 1,2 . epoxypropane (PO), a decrease in the peak of tyrosine corresponds to the appearance of a new peak $\mathrm{V}$ which covers that of phenylalanine. This was found to be due to the formation of O-(2-hydroxypropyl)tyrosine, which was identified by gas chromatography and mass spectrometry ${ }^{11}$. The silk fibroin treated with 1,2epoxybutane (BO) has the peak VII corresponding to the O-(2-hydroxybutyl)tyrosine after the peak of phenylalanine ${ }^{11}$. In the chromatograms of the samples treated with 2.3-epoxypropan-1-ol (G) and 1,2-epoxy-3-ethoxypropane (EGE), the peak (III) of O-(2,3-dihydoxypropyl) tyrosine was observed before tyrosine peak, and the peaks II and VI were identified to correspond to $0 .(3$-chloro-2.hydroxypropyl)tyrosine and 0 -(2-hydroxy-3-ethoxypropyl)tyrosine, respectively ${ }^{11}$. Moreover, the peaks I and IV may be due to $\mathrm{O}$-(2,3-dichloro-propyl)tyrosine and $\mathrm{O} \cdot[2$ hydroxy-3-(2,3-dihydroxypropoxy)propyl] tyrosine which were found in the hydrolyzate of the fibroins reacted with $G^{11}$. This result agrees with that for the hydrolyzates of the Bombyx mori fibroins treated with the same epoxides ${ }^{12-17}$.

Gas chromatography-mass spectrometry of the Bombyx mori silk fibroin samples treated with various 1,2epoxyalkanes on an $\mathrm{OV} \cdot 17$ column showed ${ }^{15}$ that major products were tyrosine adducts, i.e., 0-(2-hydroxyal * kyl)tyrosines, and that minor ones were serine adducts, i.e., O.(2-hydroxyalkyl)serines. One to one and two to one adducts of the epoxide to lysine were also found to be $\mathrm{N}^{\varepsilon} \cdot\left(2 \cdot\right.$ hydroxyalkyl) and $\mathrm{N}^{\varepsilon}, \mathrm{N}^{\varepsilon}$.bis(2-hydroxyalkyl)- lysines. In the samples ${ }^{14}$ treated with 1-aryloxy. 2,3 . epoxypropanes, O-(3-aryloxy-2-hydroxypropyl)-tyrosines and serines [except for the sample treated with 1,2. epoxy-3-phenoxypropane(PGE)], $N^{\varepsilon}$-(3-aryloxy-2.hydro. xypropyl)- and $\mathrm{N}^{\varepsilon}, \mathrm{N}^{\varepsilon}$.bis(3-arylopy-2.hydroxy-pro. pyl)lysines were identified as the main components of adducts. The adducts to glycine and alanine were also detected in the sample treated with 1,2-epoxy.3.44. methylphenoxy)propane ( $\mathrm{pTGE}$ ), indicating that the amino groups of $\mathrm{N}$-terminal amino acid residues of the Bombyx mori silk fibroin react with 1-aryloxy-2,3-epoxypropanes. Finding of 1-aryloxy-2,3-dihydroxy-propanes is considered to indicate that aspartic and glutamic acid re. sidues can react with 1-aryloxy-2,3-epoxypropanes. 3Aryloxy $2 \cdot$ hydroxypropyl- and bis(3-aryloxy-2-hydroxypropyl)-amines were found in the hydrolyzates, indicating that the arginine and glutamine residues can react with these 1 -aryloxy 2,3 -epoxypropanes ${ }^{15}$. The similar reactions seem to occur with the Philosamia cynthia ricini silk fibroin.

The silk fibroin of Philosamia cynthia ricini padded with $1 \mathrm{~N}$ aqueous solution of $\mathrm{KSCN}$ at $100 \%$ wet pickup was treated with $1.43 \mathrm{M}$ solution of $\mathrm{PGE}$ in ethanol at $68^{\circ} \mathrm{C}$. As shown in Figure 2, addition of the epoxide in. creased, and amounts of unreacted tyrosine, arginine, and histidine residues decreased with the time. The amount of lysine residue also decreased with the time, but was too small to be studied kinetically. The consumption rates of these amino acid residues were: histidine, tyro. sine , arginine.

Figure 3 shows the effect of the concentration of the catalyst in the padding solution. The sample padded with various concentrations $(0-2.0 \mathrm{~N})$ of $\mathrm{KSCN}$ aqueous solu. tion was treated with $1.43 \mathrm{M}$ solution of PGE in ethanol at $75^{\circ} \mathrm{C}$ for $3 \mathrm{hr}$. Without the catalyst, tyrosine and arginine residues did not react but histidine and lysine re sidues reacted to 64 and $73 \%$ conversions, respectively. A strong effect of the catalyst concentration was found in the reactions of the former residues, while the reactions of the latter ones did not depend markedly on the concentration of the catalyst. This finding is consistent with that with Bombyx mori fibroin ${ }^{6}$.

The above variance of the reactivity among these amino acid residues seems to be due to the difference of their dissociation abilities. The $\mathrm{pK}_{\mathrm{i}}\left(\mathrm{i}=\alpha \cdot \mathrm{COOH}, \alpha \cdot \mathrm{NH}_{2}\right.$, side group) values of tyrosine, histidine, and arginine 
are: $2.20,9.11,10.07 ; 1.82,9.17$, $6.00 ; 2.17,9.04,12.48^{18}$. No change in $\mathrm{pH}$ values of the catalyst solution was found after the padding.

In the succeeding experiment. the effect of nature of the catalyst was studied. The silk fibroin fibers were padded with aqueous solutions of a number of sodium salts at constant concentration of $1 \mathrm{~N}$, and then treated with $1.43 \mathrm{M}$ PGE solution in cyclohexane at $75^{\circ} \mathrm{C}$ for $3 \mathrm{hr}$. The reactivities of tyropine and histidine residues vary with anions of the salts from 1.16 to 54.6 and from 8.85 to $14.8 \mathrm{~mole} / 10^{5} \mathrm{~g}$, respectively, as shown in Table 1. The anions of the salts caused enhanced weight gains of the Philosamia cymthia ncini fibroin treated with $\mathrm{PGE}^{8}$. and the conversions of tyrosine and histidine residues were in the following order of efficacy: $\mathrm{CN}^{-}$, $\mathrm{N}_{3}^{-}, \mathrm{S}_{2} \mathrm{O}_{3}{ }^{-}, \mathrm{SCN}^{-}, \mathrm{I}^{-}, \mathrm{Br}^{-}$, $\mathrm{CH}_{3} \mathrm{CO}_{2}{ }^{-}, \mathrm{Cl}^{-}, \mathrm{SO}_{4}{ }^{--}, \mathrm{NO}_{3}{ }^{-}$ , $\mathrm{H}_{2} \mathrm{O}$. This kinds of effect has been already reported ${ }^{1-6}$ for the reaction of the silk fibroin of Bom. byx mori with epoxide in various solvents such as ethanol, cyclohexane, and carbon tetrachloride. Cations of the salts have been also found ${ }^{8}$ to affect the addition of epoxide to the Philosamia cynth. is ncini fibroin, but no details were studied further in this work.

The effects of the substituents of the epoxide and of the tempera-

ture were also investigated. Table 2 shows the reactivity of various epoxides towards the silk fibroin. The fibroin fibers padded with $1 \mathrm{~N} \mathrm{Na} \mathrm{S}_{2} \mathrm{O}_{3}$ aqueous solution were treated with $1.43 \mathrm{M}$ solution of various epoxides in etha. nol for 6 hr at different temperatures.

Figure 4 shows some time-conversion curves of tyro.

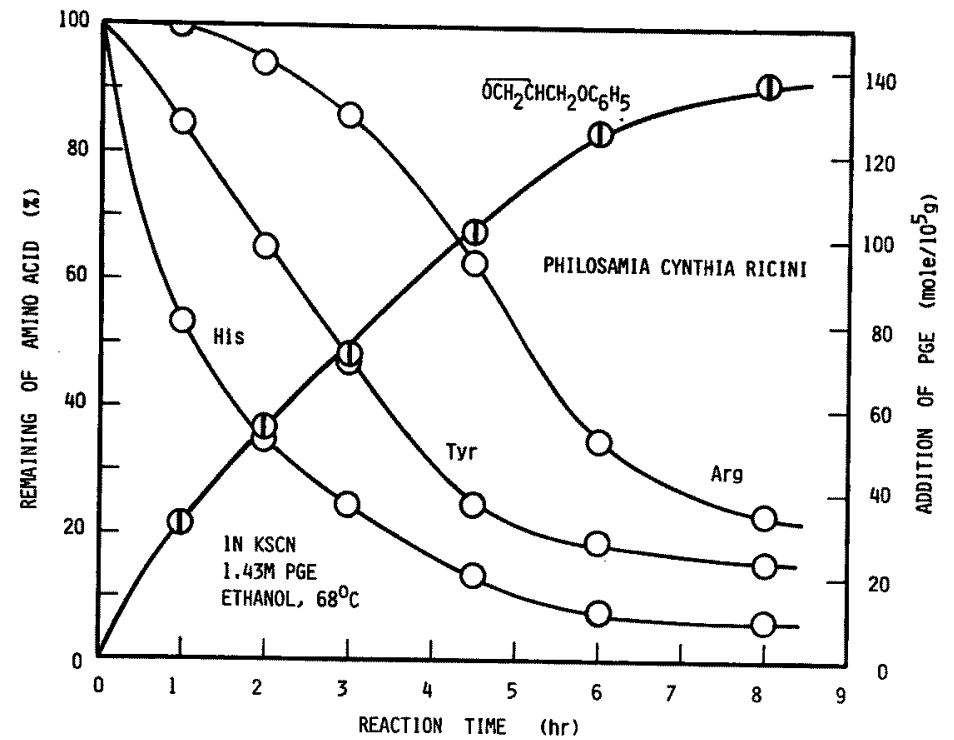

Fig. 2 Time dependences of addition of PGE and of remaining amounts of tyrosine, arginine, and histidine for the reaction of Philosamia cynthia ricini silk fibroin with $1.43 \mathrm{MPGE}$ in ethanol at $68^{\circ} \mathrm{C}$, using $1 \mathrm{~N} \mathrm{KSCN}$ aqueous solution as padding solution of catalyst.

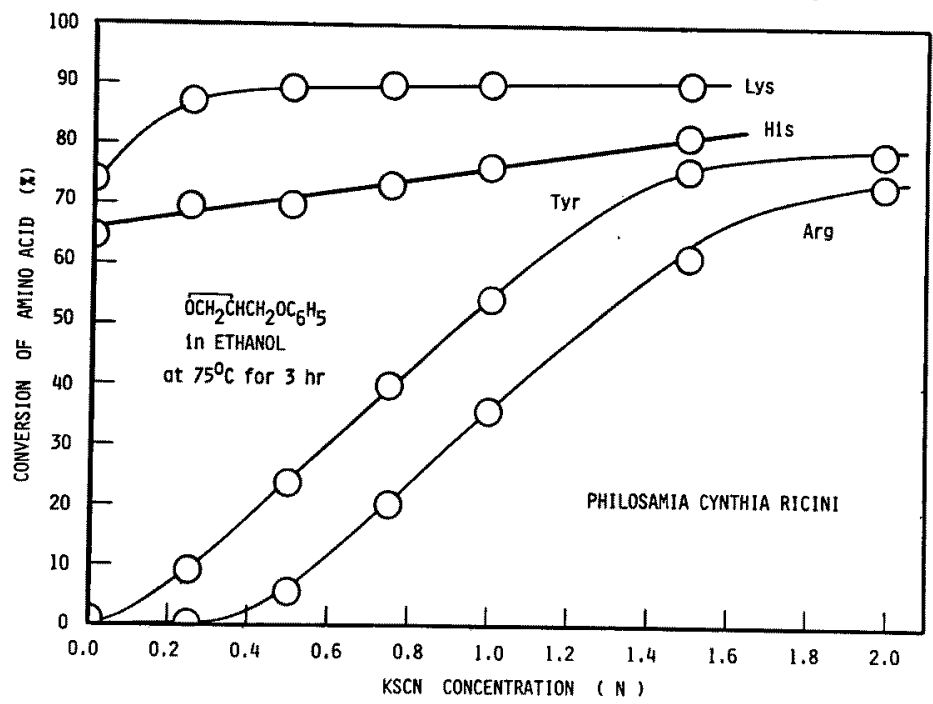

Fig.3 Effect of KSCN aqueous padding solution on reactivities of tyrosine, arginine, lysine, and histidine for reaction of Philosamia cynthia rici. ni silk fibroin with $1.43 \mathrm{M}$ PGE in ethanol at $75^{\circ} \mathrm{C}$ for $3 \mathrm{hr}$. sine in the reaction with various epoxides such as 1 . chloro-2,3-epoxypropane (E), PGE, BO, and G. The samples padded with $1 \mathrm{~N}$ aqueous solution of $\mathrm{Na}_{2} \mathrm{~S}_{2} \mathrm{O}_{3}$ at $100 \%$ pickup were treated in $1.43 \mathrm{M}$ solutions of various epoxides in ethanol at $68^{\circ} \mathrm{C}$ for $6 \mathrm{hr}$. The reactivity of these epoxides was found in the order: $E, P G E, B O, G$. 
The reactivity of $E$ towards tyrosine in Philosamia cynthia ricini fibroin is found to be much higher than that towards the Bombyx mori fibroin tyrosine ${ }^{6}$.

Tables 3 and 4 summarize the changes in the conver. sions of tyrosine and histidine residues in Philosamia cynthia ricini fibroin. The order of the reactivity of the epoxides towards histidine residue was as follows: $\mathrm{E}, 1$. bromo-2,3-epoxypropane (Eb) , $P O=G$,PGE ,1.2-epoxy3-methoxypropane (MGE) , EGE , 1.2-epoxy-3.(2propenoxy)propane (AGE), phenyloxirane ( $\mathrm{SO}$ ) $\mathrm{BO}$. The epoxides with higher basicity had greater reactivity, except for the epoxides with bulkier substituents, such as PGE, SO, and for the epoxides with smaller substituents like $\mathrm{PO}$.

In the reaction of the tyrosine residues, the higher conversion was found towards PO. E, MGE, EGE, and PGE even at lower temperature than $60^{\circ} \mathrm{C}$. while the reaction

Table 1. Salt effect on the reactivity of tyrosine and histidine for the reaction of Philosamia cynthia ricini fibroin with 1.2-epoxy-3. phenoxypropane (PGE) $)^{a}$

\begin{tabular}{|c|c|c|c|c|}
\hline \multirow[b]{2}{*}{$X^{n}$} & \multicolumn{2}{|c|}{ Conversion of Trrosine } & \multicolumn{2}{|c|}{ Conversion of Histidine } \\
\hline & mole/ $/ 10^{-1} \mathrm{~g}$ & $\%^{c}$ & mole $/ 10^{5} \mathrm{~g}$ & $\%^{d}$ \\
\hline $\mathrm{H}_{2} \mathrm{O}$ & 1.16 & 1.80 & 9.67 & 59.0 \\
\hline $\mathrm{NO}_{; 3}^{-}$ & 1.22 & 1.90 & 8.85 & 54.0 \\
\hline $\mathrm{SO}_{1}^{-\cdots}$ & 1.34 & 2.08 & 10.2 & 62.2 \\
\hline $\mathrm{CH}_{3} \mathrm{CO}_{2}^{-}$ & 5.14 & 8.00 & 10.5 & 64.0 \\
\hline $\mathrm{Cl}^{-}$ & 3.15 & 4.90 & 9.84 & 60.0 \\
\hline $\mathrm{Br}^{-}$ & 19.9 & 30.9 & 10.3 & 62.8 \\
\hline $\mathrm{N}_{3}{ }^{-}$ & 47.6 & 74.0 & 13.3 & 81.1 \\
\hline $\operatorname{SCN}^{--}$ & 33.4 & 52.0 & 11.5 & 70.1 \\
\hline $1^{-}$ & 33.4 & 52.0 & 10.4 & 63.4 \\
\hline $\mathrm{S}_{2} \mathrm{O}_{33} \cdots$ & 41.8 & 65.0 & 11.5 & 70.1 \\
\hline $\mathrm{CN}^{-}$ & 54.6 & 84.9 & 14.8 & 90.2 \\
\hline
\end{tabular}

a Silk fibroin padded with $1 \mathrm{~N}$ aqueous solution of a sodium salt was treated with 1.43 M PGE solution in cyclohexane at $75^{\circ} \mathrm{C}$ for $3 \mathrm{hr}$.

b $\mathrm{X}$ is in $\mathrm{Na}_{n} \mathrm{X} \quad(n=1$ or 2$)$.

c calculated from $64.3 \mathrm{~mole} / 10^{5} \mathrm{~g}$ for unreacted tyro. sine.

d calculated from 16.4 mole/ $/ 10^{-} \mathrm{g}$ for umreacted histidine. with SO and 1-butoxy-2,3-epoxypropane (BGE) was neg. ligible at $75^{\circ} \mathrm{C}$. The reactivity order of these epoxides was as follows: $M G E, E G E, P G E=E, P O, E b=A G E$, $\mathrm{BO}, \mathrm{G}$ " $\mathrm{SO}$ at $60^{\circ} \mathrm{C}$. This order can not be interpreted by the order of the basicity of the epoxides. The reacti vity of tyrosine towards 1-alkoxy-2,3-epoxypropanes was found to decrease with increasing length of hydro. carbon chain in the alkoxy groups.

Tables 3 and 4 also show the temperature dependence

Table 2. Temperature and epoxide dependences of epo. xide addition (mole $/ 10^{5} \mathrm{~g}$ ) in reaction of Philo. samia cynthia ricini fibroin with epoxides ${ }^{\mathrm{a}}$

Addition of epoxide (mole $/ 10^{5} \mathrm{~g}$ )

\begin{tabular}{|c|c|c|c|c|c|}
\hline Epoxide $^{b}$ & $45^{\circ} \mathrm{C}$ & $53^{\circ} \mathrm{C}$ & $60^{\circ} \mathrm{C}$ & $68^{\circ} \mathrm{C}$ & $75^{\circ} \mathrm{C}$ \\
\hline $\mathrm{PO}$ & 48 & 60 & 73 & 104 & - \\
\hline $\mathrm{BO}$ & 17 & 27 & 38 & 60 & $75^{c}$ \\
\hline iBO & $12^{c}$ & $15^{\mathfrak{e}}$ & $20^{c}$ & $26^{e}$ & $31^{e}$ \\
\hline $\mathrm{E}$ & 48 & 53 & 55 & 59 & $64^{\circ}$ \\
\hline G & 44 & 69 & 85 & 128 & $143^{r}$ \\
\hline GAm & 132 & 151 & 171 & - & 207 \\
\hline $\mathrm{Eb}$ & 22 & - & 32 & - & - \\
\hline $\mathrm{SO}$ & 10 & 17 & 27 & 42 & $80^{\circ}$ \\
\hline MGE & 89 & - & 115 & - & - \\
\hline EGE & 33 & 51 & 93 & - & 108 \\
\hline$A G E$ & 26 & 38 & 48 & 69 & $92^{c}$ \\
\hline PGE & 34 & 59 & 75 & 115 & $122^{c}$ \\
\hline pTGE & - & - & 85 & - & 129 \\
\hline PPGE & - & - & - & - & $74^{c}$ \\
\hline GMA & - & - & - & - & 71 \\
\hline $\mathrm{BGE}$ & - & - & - & - & 20 \\
\hline iPrGE & - & - & - & 57 & - \\
\hline $\mathrm{GA}$ & - & - & 68 & - & - \\
\hline $\mathrm{GAl}$ & - & - & - & 155 & - \\
\hline 00 & - & - & - & & 4 \\
\hline
\end{tabular}

a Silk fibroin padded with $1 \mathrm{~N} \mathrm{Na}_{2} \mathrm{~S}_{2} \mathrm{O}_{3}$ aqueous solu. tion was treated with $1.43 \mathrm{M}$ epoxide solution in ethanol for $6 \mathrm{hr}$ at the indicated temperature. Data from refs. 8 and 9 .

b The names of epoxides used are shown in the Experimental section of the text.

c Data in this work. 


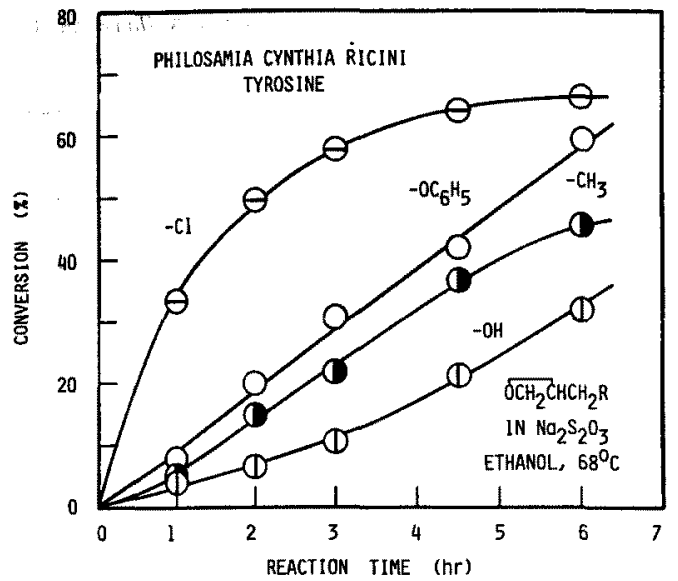

Fig. 4 Time-conversion curves of tyrosine for reaction of Philosamia cynthia ricini silk fibroin with various epoxides at $68^{\circ} \mathrm{C}$ in ethanol, using $1 \mathrm{~N}$ $\mathrm{Na}_{2} \mathrm{~S}_{2} \mathrm{O}_{3}$ aqueous solution as padding solution of catalyst. $\mathrm{R}$ in $\mathrm{OCH}_{2} \mathrm{CHCH} \mathrm{CH}_{2} \mathrm{R}$ are: $\mathrm{Cl}, \mathrm{O} ; \mathrm{C}_{6} \mathrm{H}_{5} \mathrm{O}$. $\mathrm{O} ; \mathrm{CH}_{3}, \mathrm{O} ; \mathrm{OH}, \mathrm{OD}$.

on these reactions. The reactions of tyrosine residue with $\mathrm{E}$ and $\mathrm{PGE}$, and of histidine residue with $\mathrm{E}, \mathrm{AGE}$, and $\mathrm{G}$ had smaller temperature effect than those with other epoxides under the same condition. The apparent activation parmeters were obtained as (epoxide, Ea in $\mathrm{Kcal} / \mathrm{mole}$ and $\log \mathrm{A}$ are given): $\mathrm{PO}, 9.37,1.36 ; \mathrm{BO}, 11.2,2.15 ; \mathrm{E}$, 1.91, -3.55; G, 9.88, 1.22; SO, 9.17, 0.157; PGE, 3.40. - 2.58; AGE, 9.09, 0.798 for tyrosine: $\mathrm{PO}, 7.26$ -0.442 ; BO, 10.9, 1.58; E, 0.823, - 4.60; G, 4.49, 2.28; SO, 11.5, 2.04; PGE, 7.41, -0.376; AGE, 4.25,2.55 for histidine reaction. These activation parameters are smaller than those for other epoxide reactions ${ }^{18}$, but the details are not discussed further in this study, be cause more precise kinetic analysis is now in progress.

\section{DISCUSSION}

The kinetic course of the reaction of PGE with tyrosine, histidine and arginine residues is shown in Figure 2, 5 and 6 . A sigmoidal curve is obtained by plotting the remaining amount of tyrosine or arginine residues against the reaction time and shows that the reaction has an induction period. The logarithmic relationship between the consumption rate, $\mathrm{dw} / \mathrm{dt}$, of each amino acid residues and the remaining amount, $100-W$, of the re sidue is shown in Figure 5 , where $W$ is the amount consumed given in \%. The kinetic order of the arginine or tyrosine reactions changed with the remaining amount of the residues. The order of the histidine reaction decreased monotonously with the remaining amount of the residue from 3 rd to 2 nd at the initial stage of the reac. tion. The consumption rate of tyrosine or arginine residues reaches the stationary stage, when the reaction rate reaches maximum, i.e., the rate being independent of the amount of the residue. The length of the stationary region depends on the nature of the residue.

Figure 6 shows the variations of the rate, $\mathrm{dx} / \mathrm{dt}$ (mole $/ 10^{5} \mathrm{~g} / \mathrm{hr}$ ), in ethanol at $68^{\circ} \mathrm{C}$ with the reaction time (hr). The initial consumption rates, $(d x / d t)_{t}=0$, of tyrosine and histidine residues were obtained as 6.5 and 15 $x 10^{-5}$ mole $/ \mathrm{g} / \mathrm{hr}$, respectively, by extrapolating the rate to time zero. The maximum consumption rates, $(\mathrm{dx} / \mathrm{dt})_{\max }$ of arginine and tyrosine groups were also de termined as 3.7 and $12 \times 10^{-5} \mathrm{~mole} / \mathrm{g} / \mathrm{hr}$, respectively. These values for the reaction rate of the reactive residues in Philosamia cynthia ricini fibroin are similar to those in Bombyx mori: The initial reaction rate of tyrosine, and the maximum rate of arginine and tyrosine residues in Bombyx mori fibroin were found ${ }^{6}$ to be as 6.2 , 1.3 and $13.5 \times 10^{-5}$ mole $/ \mathrm{g} / \mathrm{hr}$ in ethanol at $68^{\circ} \mathrm{C}$, re spectively. The kinetic course of the reaction shows, moreover, that the histidine reaction should not be so complicated as that of tyrosine or arginine groups. More detailed analysis of the kinetic course is now in progress and will be reported elsewhere.

Figure 7 shows the dependence of the reactivities of tyrosine and histidine residues on the Edwards nuc. leophilic parameter, $\mathrm{En}^{20}$, of anions, $\mathrm{X}^{-n}$, of the catalysts, $\mathrm{Na}_{\mathrm{n}} \mathrm{X}$. In the reactivity of tyrosine, the points for the anions with larger basicity, $\mathrm{Hn}$, such as $\mathrm{N}_{3}{ }^{-}$. were found to deviate from the linear relationship. The reactivity of histidine residue did not depend largely on the En value, suggesting that the active species are dissociated imidazole ions rather than associated ion pairs or complex in the reaction of histidine with the epoxide in the experimental condition. If the effect of the anion basicity, $\mathrm{Hn}$, is negligibly small, the following equation is obtained:

$$
\log \left(W-W_{0}\right)=a E n
$$

For the reactions of tyrosine and histidine of Philosamia cynthia ricini fibroin, a-values were obtained as 0.715 (r $=0.914)$ and $0.0533(r=0.743)$, respectively. The value for tyrosine reaction is larger than that $[a=0.506(r=$ 
Table 3. Temperature and epoxide dependences of reactivities of tyrosine in reaction of Philosamia cynthia ricimi fib. roin with epoxides ${ }^{a}$

\begin{tabular}{|c|c|c|c|c|c|c|c|c|}
\hline \multirow{3}{*}{ Epoxide $^{c}$} & \multicolumn{8}{|c|}{ Conversion of tyrosine $e^{b}$} \\
\hline & \multicolumn{2}{|c|}{$45^{\circ} \mathrm{C}$} & \multicolumn{2}{|c|}{$53^{\circ} \mathrm{C}$} & \multicolumn{2}{|c|}{$60^{\circ} \mathrm{C}$} & \multicolumn{2}{|c|}{$68^{\circ} \mathrm{C}$} \\
\hline & I & $\%$ & I & $\%$ & $I$ & $\%$ & I & $\%$ \\
\hline PO & 17.2 & 26.7 & 28.3 & 44.0 & 33.3 & 51.8 & - & - \\
\hline BO & 5.92 & 9.21 & 10.7 & 16.6 & 15.1 & 23.3 & 28.0 & 43.5 \\
\hline$E$ & 28.7 & 44.6 & 32.8 & 51.0 & 35.2 & 54.8 & 42.5 & 66.1 \\
\hline $\mathrm{G}$ & 5.34 & 8.30 & 8.68 & 13.5 & 13.5 & 21.0 & 20.6 & 32.1 \\
\hline SO & 1.22 & 1.90 & 2.51 & 3.90 & 3.99 & 6.21 & 4.44 & 6.91 \\
\hline PGE & 24.6 & 38.2 & 31.5 & 49.0 & 35.6 & 55.4 & 39.9 & 62.0 \\
\hline $\mathrm{AGE}$ & 6.43 & 10.0 & 11.6 & 18.0 & 19.6 & 30.5 & 22.5 & 35.0 \\
\hline MGE & - & - & - & - & 46.7 & 72.6 & - & - \\
\hline$E G E$ & - & - & - & - & 41.6 & 64.7 & $48.5^{\mathrm{d}}$ & $75.5^{\mathfrak{d}}$ \\
\hline $\mathrm{Eb}$ & - & - & - & - & 19.7 & 30.7 & - & - \\
\hline $\mathrm{BGE}$ & - & - & - & - & - & - & $5.52^{\mathrm{d}}$ & $8.6^{\mathrm{d}}$ \\
\hline iPrGE & - & - & - & - & - & - & $22.4^{\mathrm{d}}$ & $34.9^{\mathrm{d}}$ \\
\hline pTGE & - & - & - & - & - & - & $54.4^{\mathrm{d}}$ & $84.6^{\mathrm{d}}$ \\
\hline GMA & - & - & - & - & - & - & $49.2^{\mathrm{d}}$ & $76.5^{\mathrm{d}}$ \\
\hline GAm & - & - & - & - & - & - & $61.0^{\mathrm{d}}$ & $94.8^{\mathrm{d}}$ \\
\hline
\end{tabular}

a Silk fibroin padded with $1 \mathrm{~N} \mathrm{Na}_{2} \mathrm{~S}_{2} \mathrm{O}_{3}$ aqueous solution was treated with $1.43 \mathrm{M}$ epoxide solution in ethanol for 6 hr at the indicated temperature.

b I, conversion in mole $/ 10^{5} \mathrm{~g} ; \%$, calculated from 64.3 mole $/ 10^{5} \mathrm{~g}$ for unreacted tyrosine.

c The names of epoxides used are shown in the Experimental section of the text.

d obtained at $75^{\circ} \mathrm{C}$.

0.847)] for Bombyx mori fibroin tyrosine. The dispersion observed in this relationship suggests that another factor or Hn plays a part in the reaction catalyzed by the anions. A detailed study is now in progress and will be published elsewhere.

In the homogenous reaction of various nucleophilic species with $E$ and $G$ in solution, the nucleophilic de. pendence, a, was found to be 2.46 and 2.52 , respectively ${ }^{20}$. Thus, the effect of the anions, $X^{-n}$, on this reaction should be as small as $1 / 4$ to $1 / 3$ of those on the above reactions.

If the transition-state species for the reaction between an epoxide and functional groups of amino acid residues are of type la or Ic, the reaction should depend on the acidity of cations, $\mathrm{M}^{+n}$. The addition of the epoxide to the silk fibroin of Philosamia cynthia ricini, indeed, has been found to depend on the acidity of the cations ${ }^{8}$. Basicity may play an important part for the transitionstate species Ib, while the nucleophilic reactivity towards carbon atom, such as described by Edwards, $\mathrm{En}^{20}$ and the Swain-Scott, $\mathrm{Sn}^{21}$, must play a part for an activated complex like Id, because the steric constraint in Id should be greater than in the corresponding ion pair type Ib.

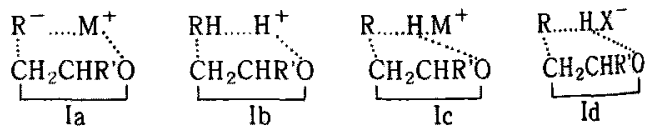

In the homogeneous reaction of epoxides in solution reaction through transition states of type $\mathrm{Ic}$ and Id bas been found ${ }^{19}$ to be affected by the counterions such as 
Table 4. Temperature and epoxide dependences of reactivity of histidine in reaction of Philosamia cymthia ricini fibroin with epoxide ${ }^{a}$

Conversion of histidine

\begin{tabular}{|c|c|c|c|c|c|c|}
\hline \multirow[b]{2}{*}{ Epoxide $^{\mathbf{b}}$} & \multicolumn{2}{|c|}{$45^{\circ} \mathrm{C}$} & \multicolumn{2}{|c|}{$53^{\circ} \mathrm{C}$} & \multicolumn{2}{|c|}{$60^{\circ} \mathrm{C}$} \\
\hline & mole $/ 10^{5} \mathrm{~g}$ & $q^{\mathrm{c}}$ & mole $/ 10^{5} \mathrm{~g}$ & $\%^{c}$ & mole $/ 10^{5} \mathrm{~g}$ & $\%^{c}$ \\
\hline PO & 7.94 & 48.4 & 10.9 & 66.5 & 13.3 & 81.1 \\
\hline BO & 2.69 & 16.4 & 3.69 & 22.5 & 5.97 & 36.4 \\
\hline $\mathrm{E}$ & 14.7 & 89.6 & 15.0 & 91.5 & 15.6 & 95.1 \\
\hline G & 9.17 & 55.9 & 11.4 & 69.5 & 12.6 & 76.8 \\
\hline so & 3.13 & 19.1 & 5.02 & 30.6 & 7.07 & 43.1 \\
\hline PGE & 7.31 & 44.6 & 9.76 & 59.5 & 12.4 & 75.6 \\
\hline AGE & 7.35 & 44.8 & 8.81 & 53.7 & 9.94 & 60.6 \\
\hline $\mathrm{Eb}$ & - & - & - & - & 15.0 & 91.5 \\
\hline MGE & - & - & - & - & 10.4 & 63.4 \\
\hline EGE & - & - & - & - & 10.1 & 61.6 \\
\hline
\end{tabular}

a Silk fibroin padded with $1 \mathrm{~N} \mathrm{Na}_{2} \mathrm{~S}_{2} \mathrm{O}_{3}$ aqueous solution was treated with $1.43 \mathrm{M}$ epoxide solution in ethanol for 6 hr at the indicated temperature.

b The names of epoxides used are shown in the Experimental section of the text.

c Calculated from $16.4 \mathrm{~mole} / 10^{5} \mathrm{~g}$ for unreacted nistidine.

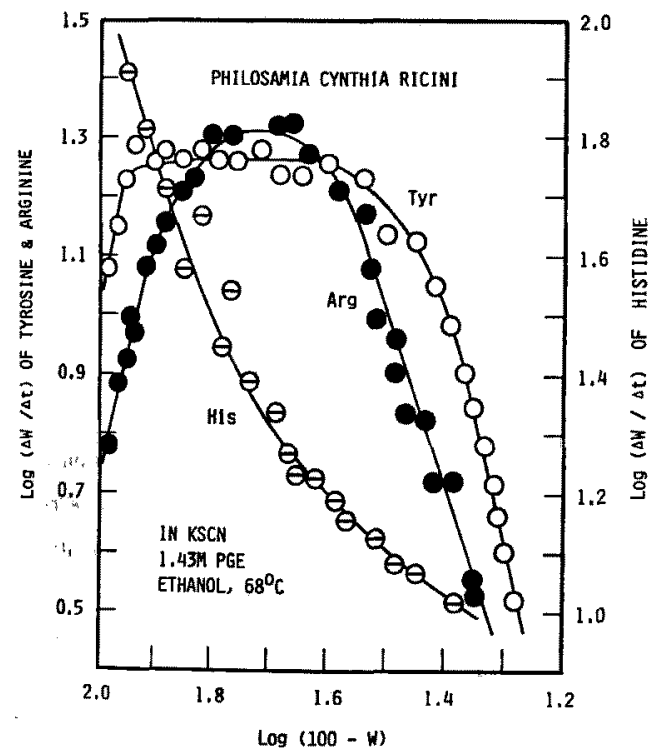

Fig. 5 Dependences of conversion rate, $\mathrm{dw} / \mathrm{dt}$, of tyrosine, arginine, and histidine on their remaining amounts, $1-\mathrm{W}$, for the reaction of Philosamia cynthia ricini silk fibroin with $1.43 \mathrm{M} \mathrm{PGE}$ in ethanol at $68^{\circ} \mathrm{C}$, using $1 \mathrm{~N} \mathrm{KSCN}$ aqueous solution as padding solution of catalyst.

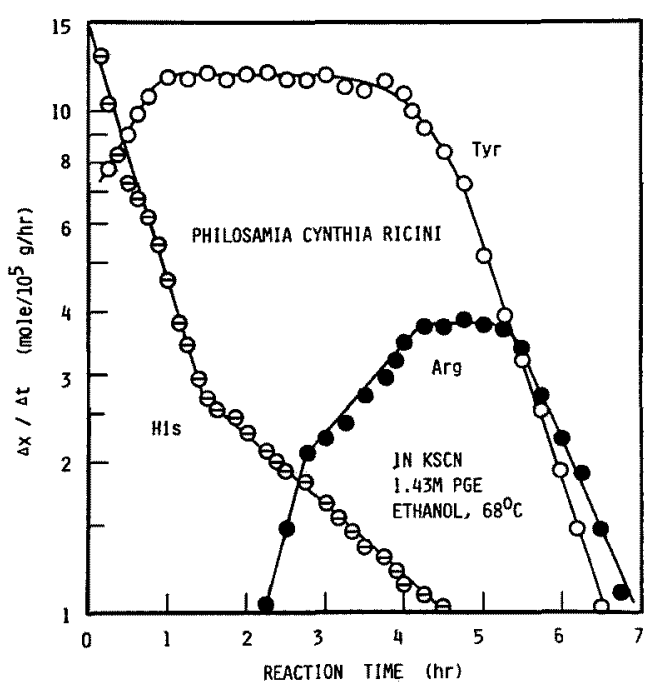

Fig. 6 Time dependences of conversion rate, $\mathrm{dw} / \mathrm{dt}$, of tyrosine, arginine, and histidine for reaction of Philosamia cynthia ricini silk fibroin with $1.43 \mathrm{M}$ PGE in ethanol at $68^{\circ} \mathrm{C}$. using $1 \mathrm{~N} \mathrm{KSCN}$ aqueous solution as padding solution of catalyst. 
$\mathrm{M}^{+}$or $\mathrm{X}^{-}$more than that through activated complexes of type la or Ib. Therefore, the reaction of dissociable histidine groups under the experimental conditions should not be affected by ions so much as the reactions of the epoxide with tyrosine and arginine residues.

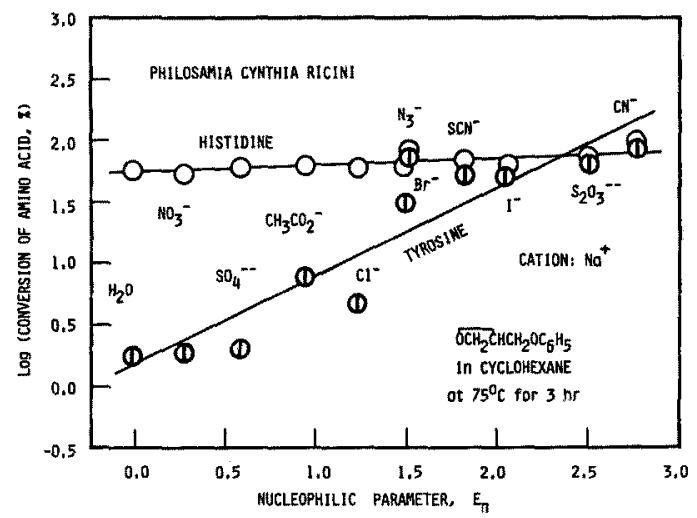

Fig. 7 Effect of nucleophilic parameter, En, of anion, $\mathrm{Na}_{n} \mathrm{X}$ ( $\mathrm{n}=1$ or 2 ), in the padding solution on the conversion of tyrosion and histidine for reaction of Philosamia cynthia ricini silk fibroin with 1.43 M PGE in cyclohexane at $75^{\circ} \mathrm{C}$ for $3 \mathrm{hr}$ : tyrosine, $\Phi$; histidine, $\bigcirc$.

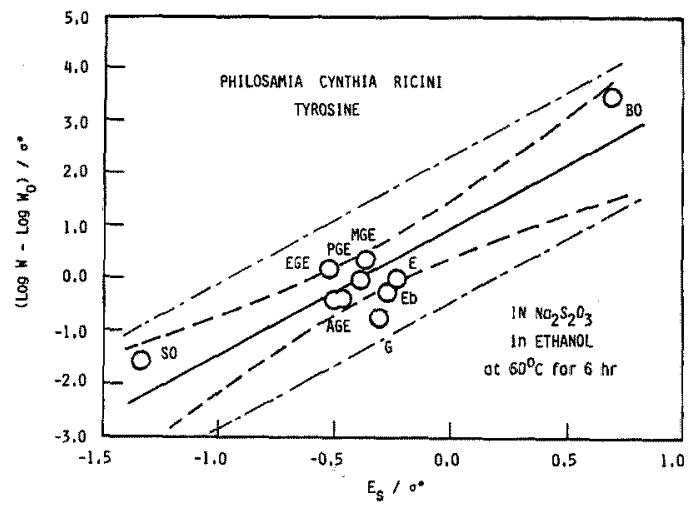

Fig. 8 Substituent effect of epoxides on the conversion of tyrosine for reaction of Philosamia cynthia ricini silk fibroin with various epoxides in ethanol at $60^{\circ} \mathrm{C}$ for $6 \mathrm{hr}$, using $1 \mathrm{~N} \mathrm{Na} \mathrm{S}_{2} \mathrm{O}_{3}$ aqueous solution as padding solution:

_-_line for $99 \%$ confidence; _..... line for $95 \%$ confidence

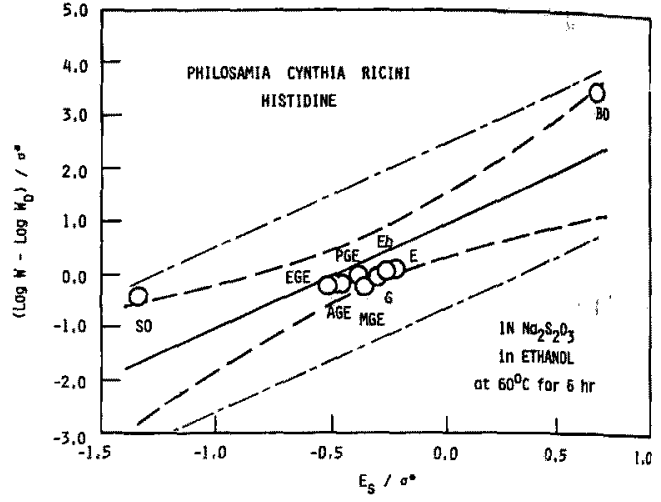

Fig. 9 Substituent effect of epoxides on the conversion of histidine for reaction of Philosamia cymthin ricini silk fibroin with various epoxides in ethanol at $60^{\circ} \mathrm{C}$ for $6 \mathrm{hr}$, using $1 \mathrm{~N} \mathrm{Na} \mathrm{S}_{2} \mathrm{O}_{3}$ aqueous solution as padding solution: --- line for $99 \%$ confidence; -... line for $95 \%$ confidence

The substituent effect of various epoxides as shown in Tables 2-4 can be put into a quantitative form for the reaction with these amino acid residues in Philosamin cynthia ricini fibroin by use of the modified Taft linear free-energy relationship ${ }^{22}$ :

$$
\frac{\left(\log W-\log W_{0}\right)}{\sigma^{*}}=\rho_{\mathrm{p}}+\frac{\rho_{\mathrm{s}} \mathrm{Es}}{\sigma^{*}}
$$

where $W_{0}$ and $W$ are the conversion of tyrosine or hist. dine in the reaction of a given compound for the same reaction of one of its substituted derivatives, and the pa. rameters, $\sigma^{*}$ and Es, are the polar and the steric substituent constants, and $\rho_{\mathrm{s}}$ and $\rho_{\mathrm{p}}$ are the reaction constants as the measures for the susceptibility of the reaction to the polar and the steric effects of the substituent, respectively.

In Figures 8 and $9,\left(\log W-\log W_{0}\right) / \sigma^{*}$ is plotted against Es/ $\sigma^{*}$ for the reaction of a series of epoxides with tyrosine and histidine, respectively. The parent compound with the conversion of $W_{\circ}$ is $P O$, for which $\sigma^{*}$ and Es are both zoro, and these values for the other epoxides are as follows ${ }^{22}$ :

BO, $-0.100,-0.070 ; G,+0.555,-0.170 ; E,+1.050$.

- 0.24; PGE, + 0.850. - 0.33; SO, + 0.600, - 0.80;

$\mathrm{EGE},+0.50,-0.26 ; \mathrm{AGE}_{\mathrm{s}}+0.65$ (or +0.60 ), -0.30 . 
Table 5. Values of $\rho_{\mathrm{s}}$ and $\rho_{\mathrm{p}}$ for reactions of tyrosine and histidine in Philosamia cynthia ricini silk fibroin with 1,2-epoxy-3-phenoxypropane (PGE) ${ }^{2}$

\begin{tabular}{|c|c|c|c|c|c|c|}
\hline & Temperature & $\rho_{\mathrm{s}}$ & $\rho_{\mathrm{p}}$ & $\mathrm{r}$ & $\mathbf{n}$ & $\rho_{\mathrm{s}} / \rho_{\mathrm{p}}$ \\
\hline \multicolumn{7}{|c|}{ Philosamia cynthia ricini } \\
\hline \multirow[t]{3}{*}{ Tyrosine } & $45^{\circ} \mathrm{C}$ & 3.26 & 1.29 & 0.916 & 7 & 2.52 \\
\hline & 53 & 2.97 & 1.13 & 0.910 & 7 & 2.63 \\
\hline & $60^{\circ}$ & 2.40 & 0.968 & 0.901 & 10 & 2.48 \\
\hline \multirow[t]{3}{*}{ Histidine } & 45 & 2.66 & 1.56 & 0.873 & 7 & 1.71 \\
\hline & 53 & 2.64 & 1.51 & 0.852 & 7 & 1.74 \\
\hline & 60 & 1.97 & 0.946 & 0.835 & 10 & 2.09 \\
\hline \multicolumn{7}{|c|}{ Bombyx mori ${ }^{\mathrm{b}}$} \\
\hline \multirow[t]{4}{*}{ Tyrosine } & 45 & 2.26 & 0.460 & 0.944 & 7 & 4.91 \\
\hline & 50 & 2.57 & 0.772 & 0.962 & 7 & 3.33 \\
\hline & 60 & 2.11 & 0.417 & 0.928 & 10 & 5.06 \\
\hline & 68 & 2.01 & 0.373 & 0.970 & 8 & 5.39 \\
\hline
\end{tabular}

a See equation 2 in the Text. Calculated from Data in Tables 3 and 4.

b Recalculated values using data in ref. 6

Es value for SO is tentatively estimated from that (0.79) for cyclohexy; Es and $\sigma^{*}$ values for EGE and AGE are those for $\mathrm{CH}_{3} \mathrm{OCH}_{2}$ and $\mathrm{C}_{6} \mathrm{H}_{5} \mathrm{OCH}_{2}$, respective ly. The best straight lines have been determined by the least-squares method and, from the intercept and the slope, $\rho_{\mathrm{p}}$ and $\rho_{\mathrm{s}}$ values are obtained as shown in Table 5. The positive value of $\rho_{D}$ indicates that electron. withdrawing substituents increase the rate, which is usually interpreted to indicate that the reaction is $S_{N} 2$, with bond-making more important than bond-breaking. The larger $\rho_{\mathrm{p}}$ values observed indicate that the steric factor in the substituents plays a more important role than polar factor in the epoxide reaction with tyrosine and histidine residues in Philosamia cynthia ricini fibroin, compared to the other epoxide reactions in homogeneous solutions. This suggests that adducts of the epoxide with these amino acid residues are not with the primary hydroxyl of $\mathrm{RCH}\left(\mathrm{CH}_{2} \mathrm{OH}\right) \mathrm{CH}_{2} \mathrm{R}^{\prime}$, but the secondary one as $\mathrm{RCH}_{2} \mathrm{CH}(\mathrm{OH}) \mathrm{CH}_{2} \mathrm{R}$ ', where $\mathrm{R}$ is an organic group such as $-\mathrm{COO},-\mathrm{NH},-\mathrm{N},-\mathrm{O}$ of amino acid residue in fibroin and $\mathrm{R}^{\prime}$ is a substituent of the epoxide, $\mathrm{OCH}_{2} \mathrm{CHCH}_{2} \mathrm{R}$ '. The latter type adducts of lysine has been found in the reaction of $\mathrm{PO}$ with Bombyx mori fibroin ${ }^{15}$. Moreover, the value of $\rho_{\mathrm{s}} / \rho_{\mathrm{p}}=2.5-2.6$ for the tyrosine reaction is larger than that, $1.7-2.1$, for the histidine, showing that the activated species of histidine should be of type la or Ib. The values for the tyrosine in Philosamia cynthia rici$n i$ is much smaller than those, 3.3-5.4, in the Bombyx mori fibroin, and is associated with larger intermicellar distance and significant ability of the Philosamia cymthia ricini fibroin to swell with aqueous solutions ${ }^{7}$, although the reactivity of functional amino acid residues in fibroins may depend on the variation in the form of the samples, i.e., fiber or fabrics.

\section{REFERENCES}

1. H. Shiozaki and Y. Tanaka, J. Polym. Sci. B, 7, 325 (1969).

2. Y. Tanaka and H. Shiozaki, Makromol. Chem., 12912 (1969).

3. H. Shiozaki and Y. Tanaka, $J$. Polym. Sci. A-1, 8, 2791 (1970).

4. H. Shiozaki and Y. Tanaka, Makromol. Chem., 143, 25 (1971).

5. H. Shiozakı and Y. Tanaka. Makromol. Chem., 152, 217 (1972).

6. H. Shiozaki and Y. Tanaka, J. Sericul. Sci.Jpm., 45, 74 (1976).

7. J. Kirimura, Bull. Sericul. Exp. St., 17, 447 (1962): K. 
Komatsu, in "Structure of Silk, II" (N. Hojo, ed.) Shinshu Univ., Ueda, 1980, p. 352.

8. Y. Tanaka and H. Shiozaki, J. Polym. Sci. Polym. Chem. Ed., 12, 2741 (1974).

9. H. Shiozaki and Y. Tanaka, Angew. Makromol. Chem., 64, 1 (1977).

10. K. Hirabayashi, E. Suzuki, H. Ishikawa, and Y. Go, J. Sericul. Sci. Jpn., 37, 347 (1968).

11. Y. Tanaka and H. Shiozaki, Unpublished results.

12. M. Sakamoto, K. Kajiyama, H. Shiozaki, and Y. Tanaka, Sen-i Gakkaishi, 31, T.158 (1975); ibid,, 32, T335 (1976).

13. M. Sakamoto, K. Kajiyama, F. Nakayama, H. Shiozaki, and Y. Tanaka, Sen-i Gakkaishi, 33, T.540 (1977).

14. M. Sakamoto, N. Tsuji, F. Nakayama, and K. Kajiyama, J. Chromatogr., 235. 75 (1982).

15. M. Sakamoto, N. Kohara, M. Wakabayashi, and F. Nakayama, Nippon Kagaku Kaishi, 1207 (1983); ibid.,
1442 (1984).

16. M. Sakamoto, N, Kohara, M. Wakabayashi, M. Nishimoto, and F. Nakayama, Sen-i Gakkaishi, 40, T.113 (1984).

17. M. Sakamoto, M. Wakabayashi, and N. Kohara, Sen. i Gakkaishi, 41, T.156 (1985).

18. M. Windholz, S. Budavari, R. F. Blumettí, E. S. Otterbein, "Merk Index" 1Oth Ed., Merk, Rahway, 1983.

19. Y. Tanaka and T. F. Mika, in "Epoxy Resins", (C. A. May and Y. Tanaka, ed.), Dekker. New York, 1973, Chapter 3 .

20. J. O. Edwards, J. Amer. Chem. Soc., 76, 1540 (1954); ibid., 78, 1819 (1956).

21. C. G. Swain and C. B. Scott, J. Amer, Chem. Soc., 75, 141 (1953)

22. R. W. Taft, Jr., in "Steric Effects in Organic Chemistry". (M. S. Newman, ed.), Wiley, New York, 1956. p. 556.

\title{
エリ蚛絹フィブロインの官能性アミノ酸 側鎖に対するモノエポキシドの反応性
}

\author{
瀻維高分子材料研究所 田中芳雄 \\ 神奈川県䋐維工業指遒所 湓崎英街
}

触媒として中性塩水溶液を含浸したエリ䖝絹つィプロ インと種々モノエポキシドとの不均一系付加反応をエ夕

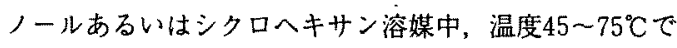
検討した。主要な官能性アミノ酸側鎖の反応性は次の順 に低下した：His>Tyr >Arg。Tyr 抢よびArg 側鎖の反 応では含浸中性塩の濃度効果が顥著であったが，Hisや
Lys 側鎖の反心には中性塩漕度はほとんど影響しなか力 た。Tyr 側鎖の反応は含浸中性塩の陰イオンの求核性に よって説明できた。更にTyr 拈よび His 溉鎖の反店に 対するエポキシドの置換基効果を修正 Taft 式を用いて 議諭した。又家蚕絹フィブロインの反応性との差異を考 察した。 